\title{
Efficacy of cognitive rehabilitation therapy on stress and anxiety of the high school second level female students
}

\author{
Leili Akhlaghi Jami ${ }^{1}$, Peyman Hassani-Abharian ${ }^{2 *}$ iD , Hasan Ahadi ${ }^{3}$, Alireza Kakavand ${ }^{4}$
}

\begin{abstract}
1. PhD Student of General Psychology, Department of Psychology, Karaj Branch, Islamic Azad University, Karaj, Iran
2. Assistant Professor, Department of Cognitive Rehabilitation, Brain and Cognition Clinic, Institute for Cognitive Science Studies, Tehran, Iran

3. Professor, Department of Psychology, Karaj Branch, Islamic Azad University, Karaj, Iran

4. Associate Professor of Psychology, Department of Psychology, Faculty of Social Science, Imam Khomeini International University, Qazvin, Iran
\end{abstract}

Recieved: 18 Jun. 2019

Revised: 21 Oct. 2019

Accepted: 5 Nov. 2019

Keywords

Cognitive rehabilitation therapy (CRT)

Anxiety

Stress

Students

Corresponding author

Peyman Hassani-Abharian, Assistant Professor, Department of Cognitive Rehabilitation, Brain and Cognition Clinic, Institute for Cognitive Science Studies, Tehran, Iran

\section{Email: Abharian@iricss.org}

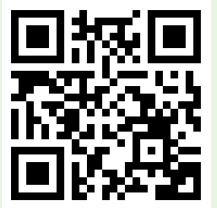

\section{Abstract}

Introduction: Anxiety and stress degraded the cognitive function of tasks involved in working memory and decreased working memory capacity and efficiency. Working memory is a complex, limited-capacity cognitive system that prepares information to be stored while processing it simultaneously. One of the new therapeutic approaches whose effectiveness in the reduction of stress and anxiety might be considered is cognitive rehabilitation; the efforts to repair cognitive deficits. This study is designed to evaluate the efficacy of cognitive rehabilitation therapy (CRT) on stress and anxiety of the high school second lever female students in Tehran.

Methods: The following study is a semi-experimental study with pretest- posttest and control group with a follow-up stage. The target society of this research includes female students with symptoms of anxiety and stress at the second level of high school in Tehran during the academic year of 2018-2019. The participants are 30 female students in two matched groups (15 participants within the experimental group and 15 ones in the control group) selected by the available sampling method. The experimental group received eight sessions of 90 minutes of individual CRT intervention using computer-based cognitive rehabilitation software. The control group did not have any type of intervention and recruited from the waiting list. The measurement instrument was the depression anxiety and stress scale (DASS-21) distributed in three different periods of time (pretest, posttest, and follow-up stages. The obtained data were analyzed by SPSS-22. Indicators such as mean and standard deviation and multivariate analysis of covariance were used. The Levin test helped us to check the homogeneity of variances. Results: The results indicated that the CRT method of intervention effectively reduced the high school second level female students' stress and anxiety. However, just its effect on anxiety remained persistent untill the follow-up period.

Conclusion: CRT method effectively affects the anxiety and stress of high school second level female student, and it might be considered as a useful way in the field.

Citation: Akhlaghi Jami L, Hassani-Abharian P, Ahadi H, Kakavand A. Efficacy of cognitive rehabilitation therapy on stress and anxiety of the high school second level female students. Advances in Cognitive Sciences. 2020;22(2):111-119. 


\title{
بررسى اثربخشى درمان توانبخشى شناختى در كتترل استرس و اضطراب دانش آموزان دختر دوره دوم دبير ستان
}

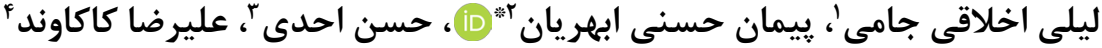

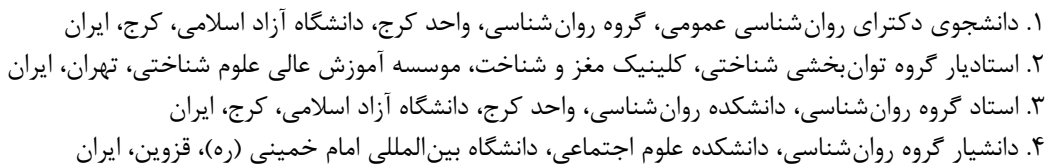

\section{ars}

مقدمهه: استرس و اضطراب عملكرد شناختى تكاليف دركير در حافظه فعال را تخريب كرده، اثرات كاهشى بر ظرفيت حافظه فعال داشته و از كارايى آن مى كاهد. يكى از رويكردهاى درمانى جديد كه اثربخشى آن در كاهش استرس و اضطراب قابل بررسى است، توانبخشى شناختى و تلاش جهت ترميم نقايص شناختى است. يروهش حاضر با هدف بررسى اثربخشى ري درمان توانبخشى شناختى در كنترل استرس و اضطراب دانش آموزان دختر دوره دوم دبيرستان شهر تهران انجام شده است. روش كار: روش يزوهش نيمه تجربى با طح يِيش آزمون و پِس آزمون با گروه كنترل و پِيخيرى بود. جامعه يُروهش متشكل از دانش آموزان دختر با نشانه هاى اضطراب و استرس كه در مقطع دوره دوم دبيرستان شهر تهران در سال تحصيلى لوسجا -

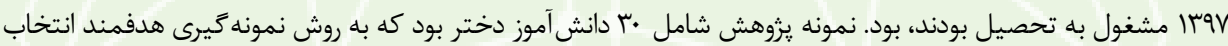
و در دو كروه آزمايش و كنترل قرار كرفتند. كروه آزمايش توسط نرمافزار توانبخشى شناختى Captain's Log در 1 جلسه •ج دقيقهاي به صورت فردى مورد مداخله قرار كرفتند، در صورتى كه هييج مداخلهاى روى گروه كنترل انجام نكَفت. ابزار يزوهش يرسشنامه DASS-21 بود كه دو تروه، در سه مرحله آن را تكميل نمودند. دادهها با استفاده از آزمون تحليل كوواريانس جند متغيرى و به وسيله نرمافزار SPSS-22 تجزيه و تحليل شدند. يافتهها: نتايج يزوهش نشان داد كه درمان توانبخشى شناختى حافظه فعال تأثير معنادارى در كاهش استرس و اضطراب دانش آموزان در مرحله يس آزمون و پيیخيرى دارد. نتيجه كَيرى: بر اساس يافتهاى يُوهش حاضر مى توان نتيجه كرفت كه درمان توانبخشى شناختى حافظه فعال در كاهش استرس و اضطراب دانشآموزان دختر مؤثر است، در نتيجه مى توان جهت كاهش استرس و اضطراب آنها از اين

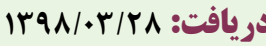

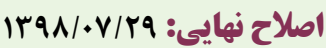
يذيرش: وازمهاى كليدى توانبخى شناختى استرس

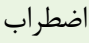
دانش آموزان نويسنله مسئول دكتر ِيمان حسنى ابهريان، استاديار كروه توانبخشى شناختى، كلينيك مغز و شناخت، موسسه آموزش عالى علوم شناختى، تهران، ايران ايميل:Abharian@iricss.org

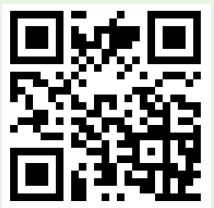

dol doi.org/10.30699/icss.22.2.111

مقلدمه

به مشكلات شناختى مربوط مىشود، مانند حواسيرتى فراوان و عدم تمركز (1). با اين حال، شناخت مىتواند بر اضطراب تأثير بخذارد، شناخت يك ويزگى است كه براى درمان اختلالات اضطرابى مورد توجه قرار مى گيرد (r). بنابراين درك درست از مكانيزمهاى شناختى كه موجب كاهش اضطراب مىشوند، مىتواند ييامدهاى بالينى مهمى را
اضطراب اغلب پاسخى به يك ييامد آزاردهنده غير قابل پيشبينى و نامشخص در نظر كرفته مىشود (1). حالتهاى اضطرابى هم اجزاء فيزيولوزيكى (برانگيختخى) و هم اجزاء روانشناختى (نگرانى) را در بر مى گيرند (ז). رابطه بين شناخت و اضطراب ييجيده است. به عنوان مثال، برخى از شكايات مههم افراد مبتلا به اختلالات اضطرابى 
و اثرات آن بر فرايندهاى شناختى نوجوانان امرى ضرورى است. يكى از رويكردهاى درمانى جديد كه اثربخشى آن در كاهش استرس و اضطراب

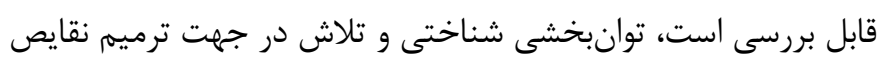

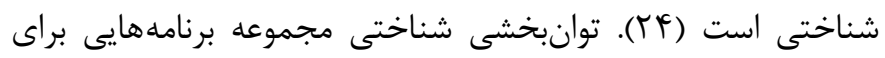

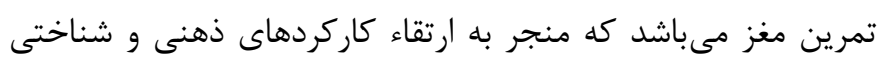

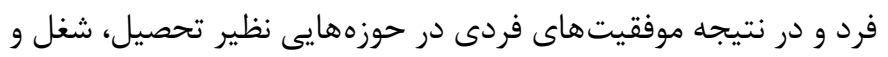

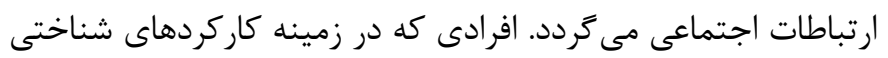

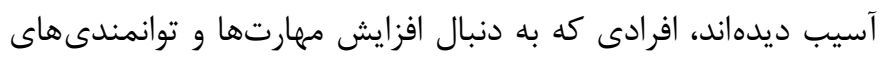
ذهنى هستند نيز از اين برنامهها براى ارتقا عملكرد خود استفاده مى كنند؛ لذا توانبخشى شناختى يك فرايند آموزشى در راستاى ارتقا

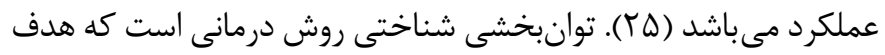

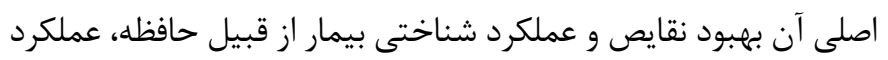

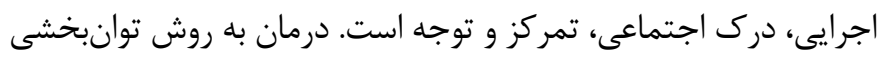

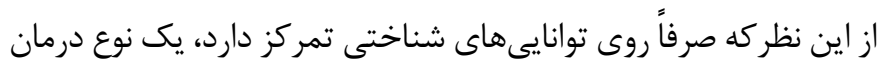

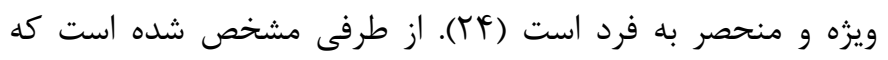

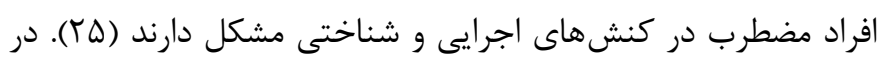
مجموع به نظر مى سد درمان توانبخشى شناختى حافظه فعال مداخله اثربخشى براى بهبود كاركردهاى شناختى، اضطراب و افسردىى بيماران دجار آسيب مغزى، وسواسى جبرى، بيشفعالى و نقصتوجه و اختلالات

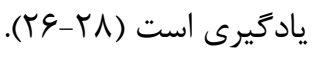

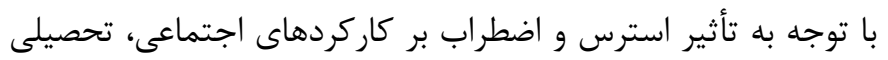

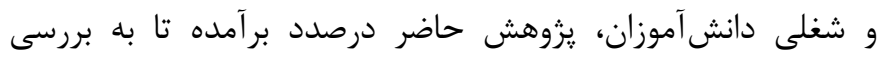

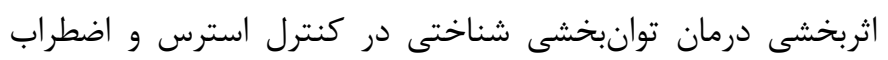

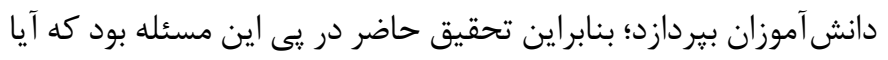

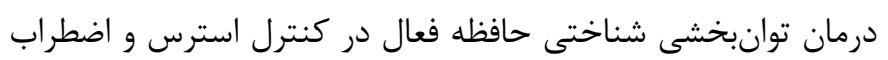

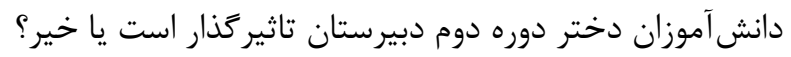

\section{روش كار}

روش يزوهش حاضر نيمهتجربى با طرح يِيشآزمون و پس آزمون با

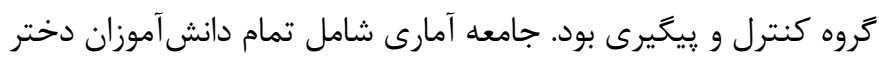

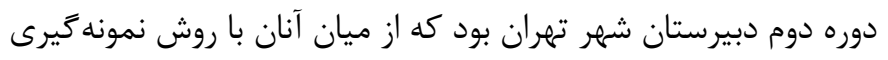

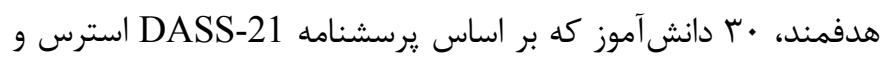

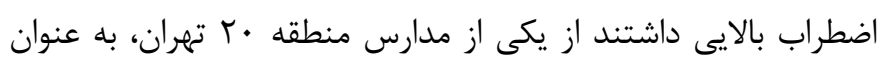

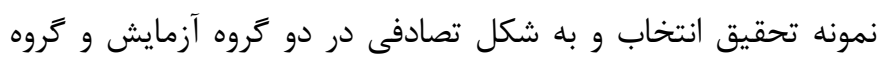

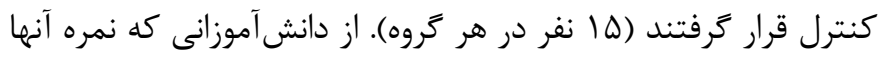

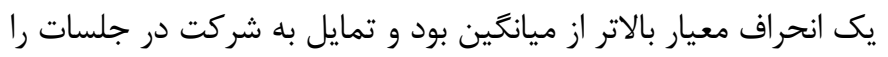
داشتند مصاحبه فردى به عمل آمد و پِس از مصاحبه بالينى و در نظر
جهت يِشگيرى و درمان اين اختلالات به همراه داشته باشند. اضطراب

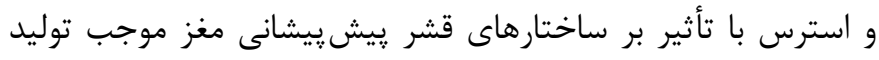

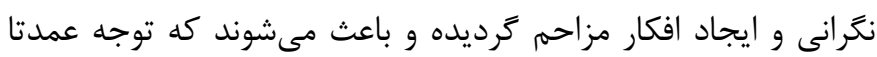

جلب محرك هاى تهديدآميز تردد (\$) أ).

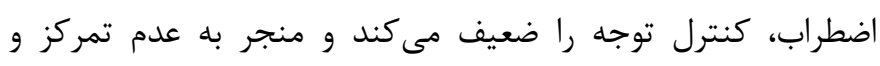
حواسيرتى مىشود. كنترل توجه يكى از اجزاء كليدى ادراك انسان

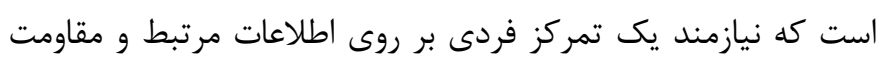

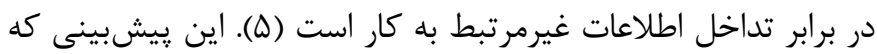
اضطراب كنترل توجه را ضعيف مى كند توسط تحقيقات بسيارى مورد

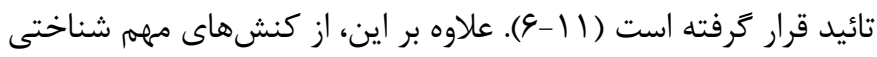
كه در منطقه قشر سينكَوليت قدامى يردازش مى گردد، عملكرد حافظه

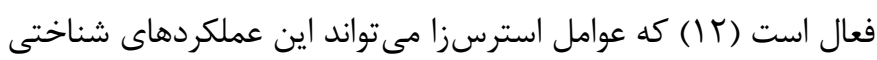

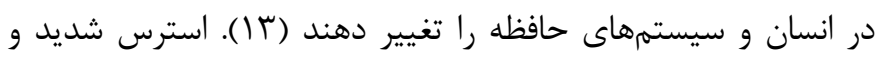

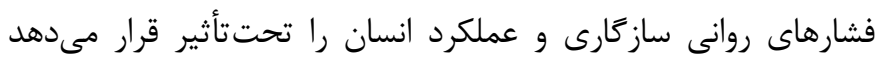

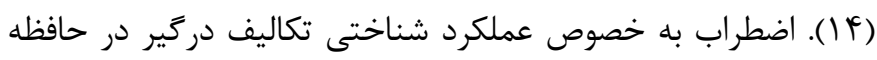

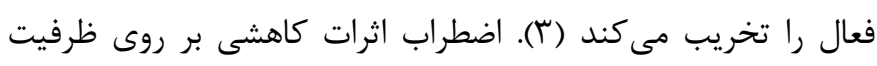

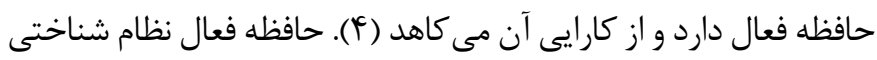

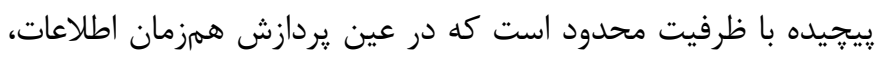

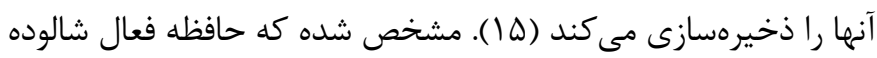

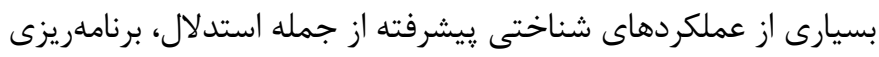

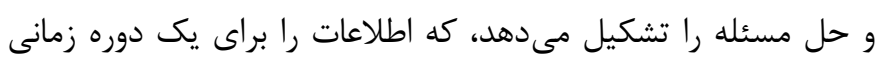
كوتاه در آن ذخيره و دست كارى مىشود. به عبارت ديكَ دئر حافظه فعال

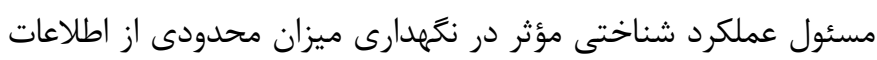

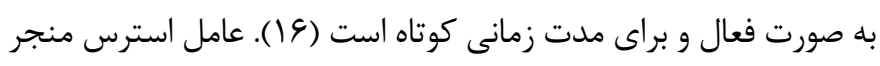

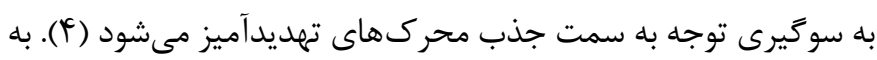

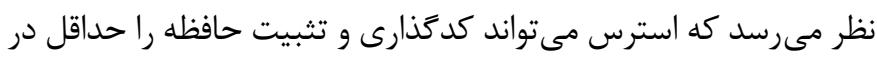
مواقعى كه مواد يادگيرى محتواى عاطفى دارند تسهيل كند، در حالى كه

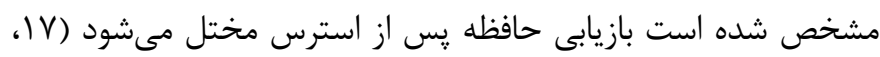

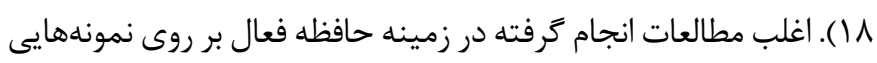

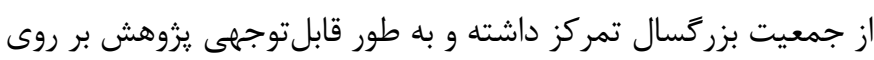

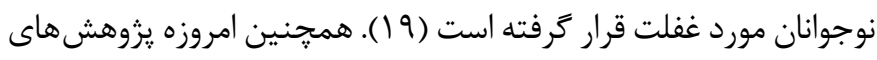

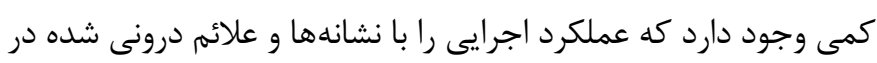

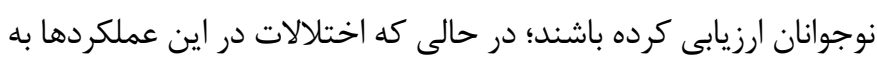

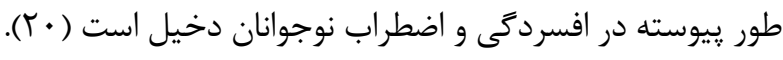

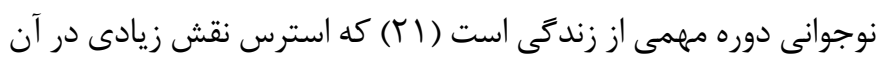

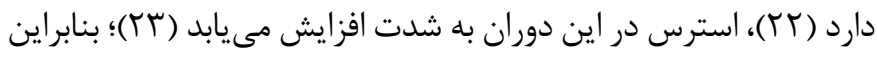

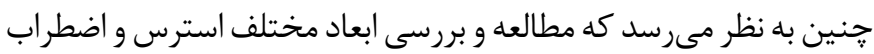




\section{نرمافزار توانبخشى شناختى Captain's Log نسخه 11/r؟: اين}

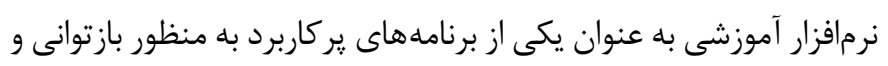

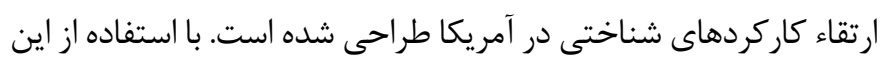

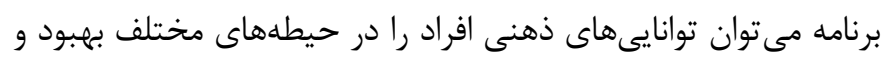

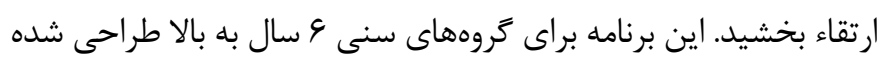

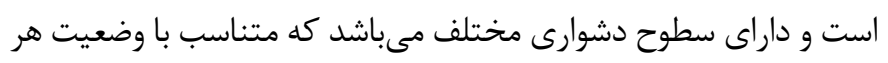

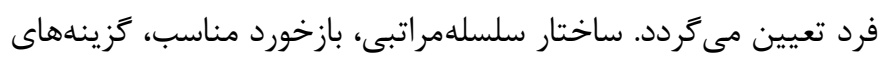

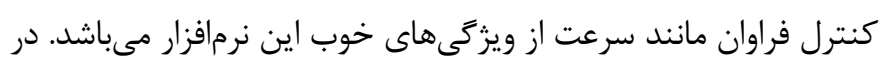

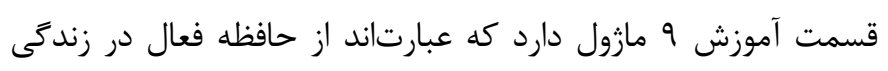

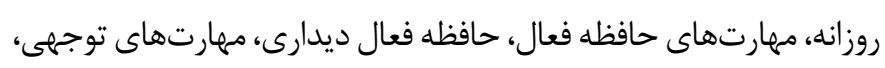

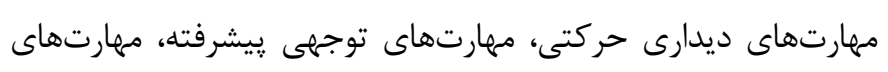

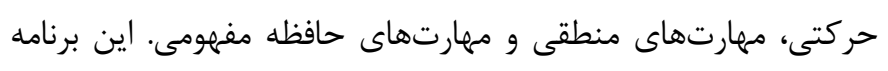

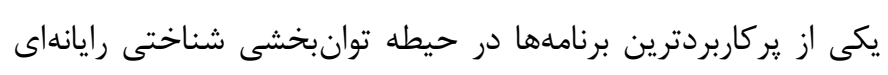

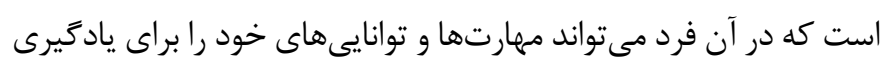
و كسب موفقيت در حيطههاى مختلف زندگى روزمره، زندكى تحصيلى

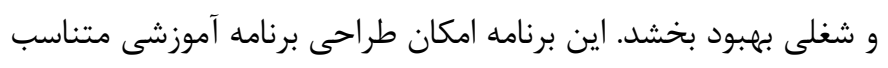
با شرايط فرد را داراست و مىتواند براى هر فرد برنامههاى درمانى بـ باني تمرينات مختلف و تنظيمات كوناكون در نظر كرفت در اين يزوهش نوع مداخله دريافتى به عنوان متغير مستقل و كاهش

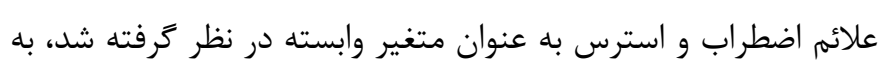
اين شكل كه قبل و بعد از اجراى مداخله مقياس

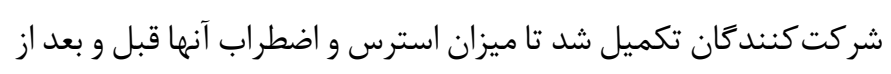

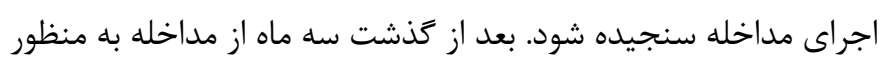

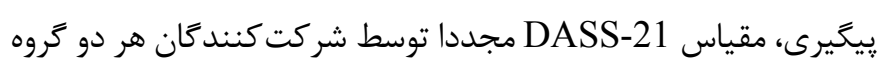

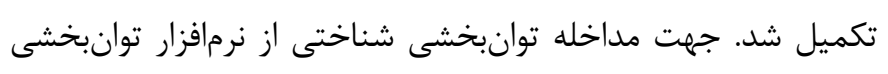

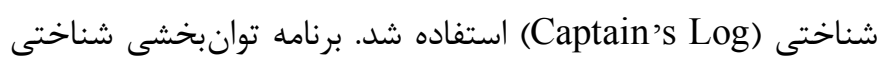

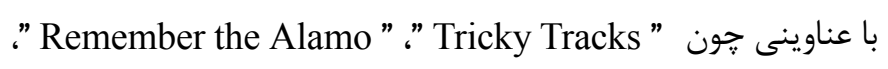
"Where is my car?" از مازول حافظه فعال و بازى" "Match Play"

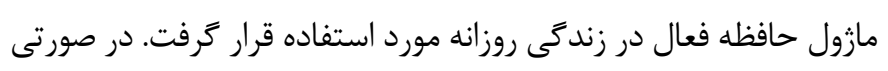

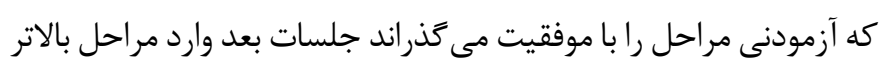

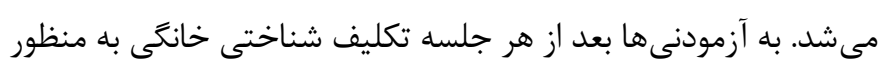
تقويت شناختى نيز داده مىشد.

\section{يافته ها}

اين يزوهش روى · ب نفر از دانش آموزان دختر دوره دوم دبيرستان كه در

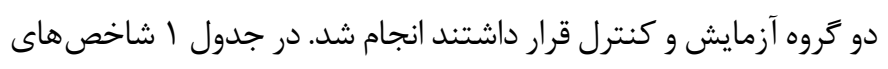
توصيفى متغيرها براى نمونه مورد بررسى، شامل ميانگين و انحراف معيار
كرفتن ملاكهاى ورود و خروج، به طور تصادفى در زروه آزمايش و

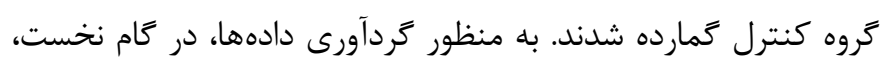

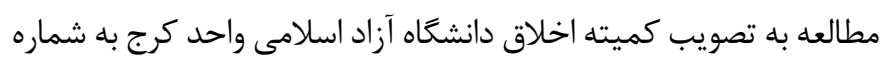

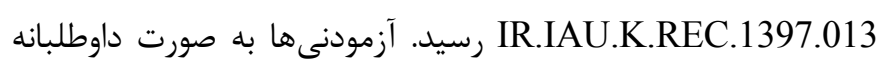

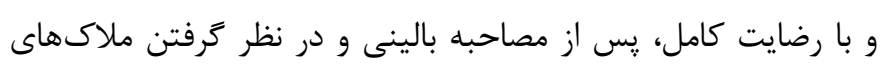

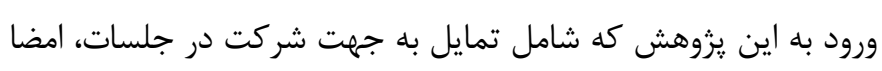
تعهدنامه شركت مستمر در جلسات درمانى، ير كردن فرم رضايت آكاهانه

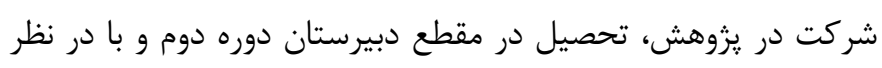

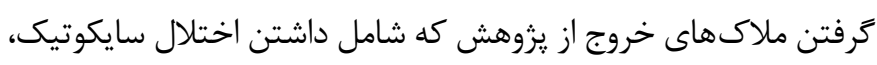

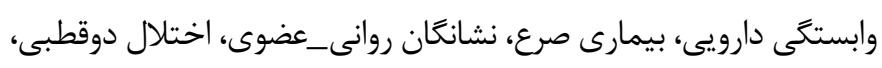

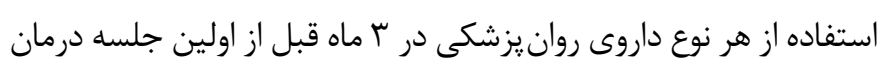

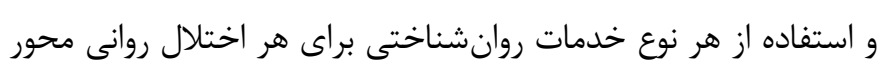

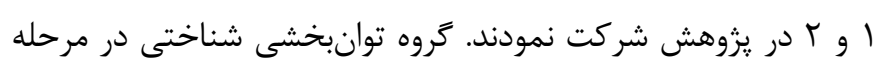

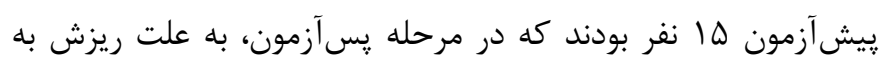

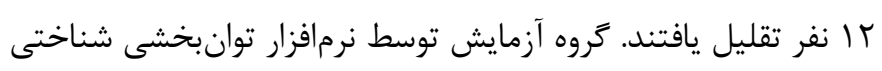
Captain's Log

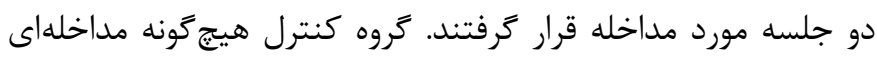

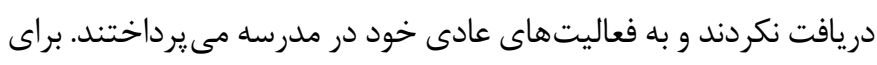

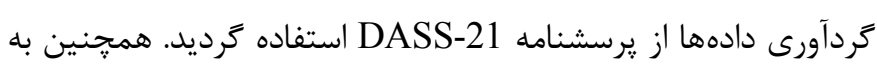

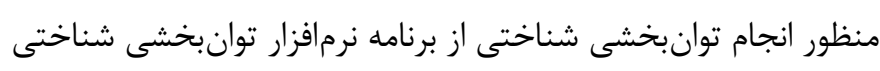

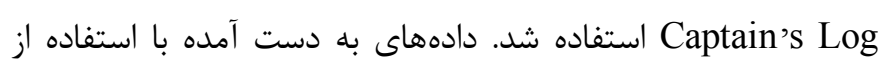
روش آمارى توصيفى و استنباطى و به وسيله نرم افزار SPSS-22 كرديدند. در بخش توصيفى به توصيف متغيرهاى يزوهش بو با استفاده از

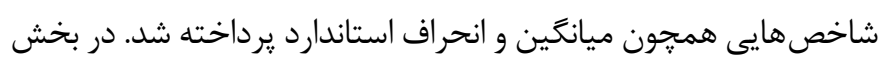

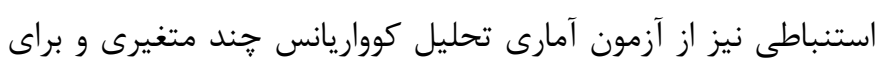
بررسى بيش فرض همخنى واريانس ها از آزمون لوين استفاده شد. فرم كوتاه مقياس افسردكى، اضطراب و استرس (DASS-21)

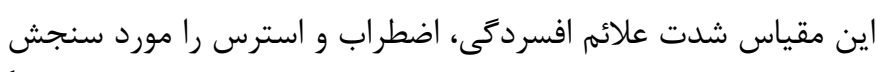

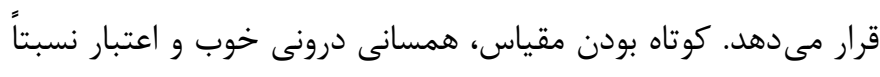

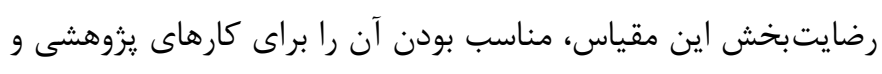

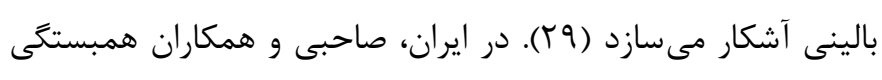

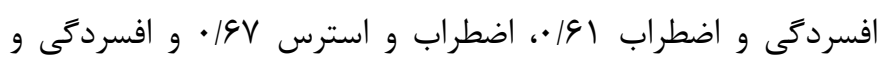

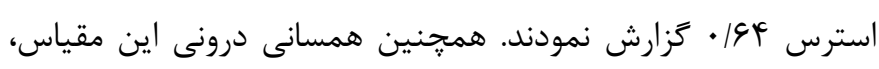

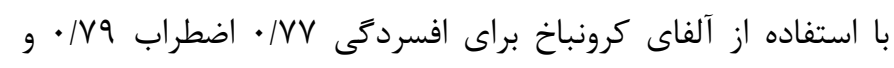

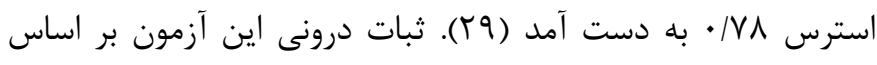

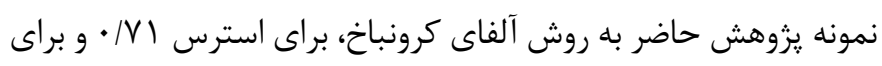

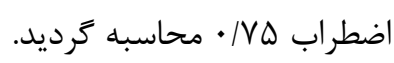


آزمايش، در مرحله يُآزمون و پِيگيرى كمتر از پِيش آزمون است و اين نشان مىدهد كه درمان توانبخشى شناختى باعث كمتر شدن سطح استرس و اضطراب نمونه يزوهش شده است. همجنين مقدار كجى و كشيدگى متغيرها نشان از نرمال بودن دادهاى يزوهش است.
در پِيش آزمون و يس آزمون و پِيخيرى به تفكيك گروهها ارائه شده است. در جدول ا ميانگين و انحراف معيار متغيرهاى بزوهش به تفكيك گروهها در سه مرحلهى پيشآزمون، پِ آزمون و پِيخيرى گزارش شده است.

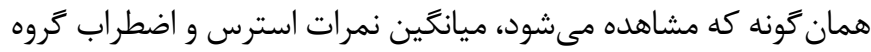

جدول ا. آمارههاى توصيفى متغيرهاى يزوهش به تفكيك كروهها

\begin{tabular}{|c|c|c|c|c|c|c|}
\hline كشيدكى & كجى & انحراف معيار & ميانگَين & وضعيت & تروه & شاهد \\
\hline$-\cdot / q V$ & .1 .99 & r/QVF & $|q / F| s$ & ِيش آزمون & \multirow{3}{*}{ آزمايش } & \multirow{6}{*}{ استرس } \\
\hline$-\cdot|Q| r$ & $-\cdot / r \cdot \Delta$ & T/TYA & זr/N & ֶس آزمون & & \\
\hline$-\cdot 19 \Delta V$ & $\cdot \mid \Delta V Y$ & $F / F \Delta F$ & N/ra. & بيخيرى & & \\
\hline$-1 / 1 F r$ & $\cdot / 1 \cdot r$ & $r / \Delta \Delta V$ & $\mid \psi / q \ldots$ & ِيش آزمون & \multirow{3}{*}{ كنترل } & \\
\hline$-\cdot \mid \Delta T \Delta$ & $-\cdot \mid \Delta \wedge r$ & F/TAt & $\mid r / r 99$ & هس آزمون & & \\
\hline$-11 \cdot 91$ & $-\cdot / F \vee \Delta$ & f/lrq & 1 1r/499 & ِيخيرى & & \\
\hline.$- / 919$ & $-\cdot / r g F$ & T/TG. & $|r / 9| 9$ & ِيش آزمون & \multirow{3}{*}{ آزمايش } & \multirow{6}{*}{ اضطراب } \\
\hline$\cdot \mid \Delta \cdot r$ &.$/ 991$ & $F / \Delta \cdot 1$ & $91 \cdot \lambda r$ & يُ آزمون & & \\
\hline - . / FTt & $\cdot / 4 \cdot \Delta$ & $F / .4 \Delta$ & $\Delta$ & بيخيرى & & \\
\hline$-\cdot / T \Delta T$ &.$/ 1 \Upsilon \Lambda$ & r/T\&A & $\mid r / q \ldots$ & ِيش آزمون & \multirow{3}{*}{ كنترل } & \\
\hline.$- / 11 r$ & $-\cdot / V \Delta V$ & F/TRT & س & يس آزمون & & \\
\hline$-\cdot / 199$ & $-\cdot / 191$ & $r / D F q$ & $11 / \pi \cdot$ & ييكيرى & & \\
\hline
\end{tabular}

فرض همكنى شيب ركرسيون برقرار خواهد بود كه ميان متغيرهاى

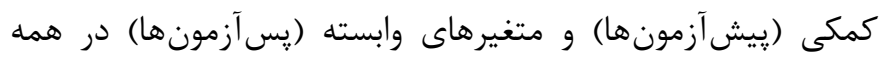

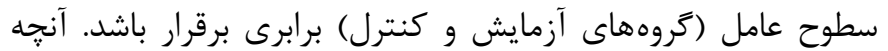
مورد نظر است تعامل غير معنادار بين متغيرهاى هميراش (كواريته)

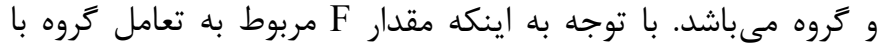
يُش آزمون براى متغيرهاى يزوهش معنادار نيست؛ در نتيجه مفروضه همخنى شيبهاى ركرسيون رعايت شده است. با توجه به بر قرار بودن مفروضه هاى مانكوا، نتايج اين آزمون در جدول ب كَزارش شده است.

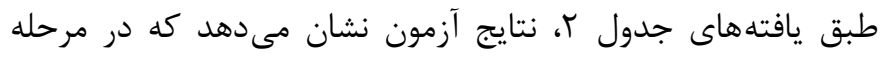

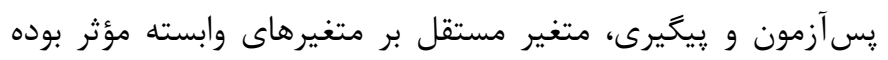

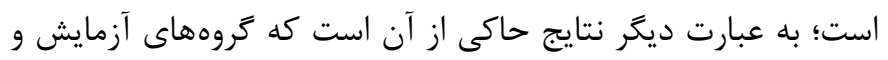
كنترل حداقل در يكى از متغيرهاى استرس و اضطراب تفاوت معنادارى

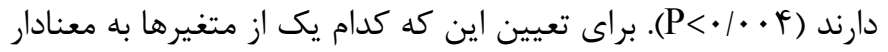
بودن نتيجه نهايى كمك كرده است، نتايج حاصل از تحليل كوواريانس
جهت آزمون فرضيه يزوهش مبنى بر اينكه رواندرمانى توانبخشى

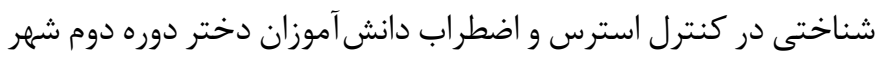
تهران مؤثر است يا خير؟ از آزمون تحليل كوواريانس جندمتنغيره استفاده شد. يِش از تحليل دادها به روش تحليل كوواريانس جندمتغيرى، به دليل كنترل اثر بيش آزمون، پِيشفرضهاى اين آزمون مورد ارزيابى

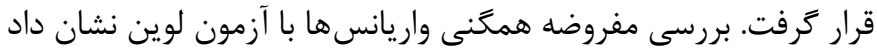
كه اين مفروضه بر قرار است. آزمون لوين براى هيج كدام از متغيرها

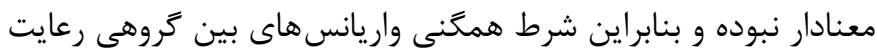

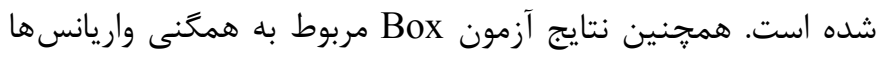

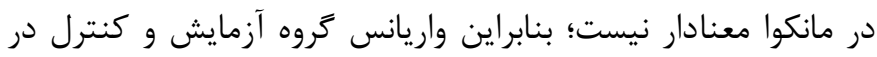
متغيرهاى استرس و اضطراب به طور معنادار متفاوت نيستند و فرض درض همخنى وار يانس ها تاييد مىشود. در اين يروهش پِّآزمونهاى استرس و اضطراب به عنوان متغير وابسته و يِيش آزمون هاى آنها به عنوان متغير كمكى تلقى شدند. زمانى 


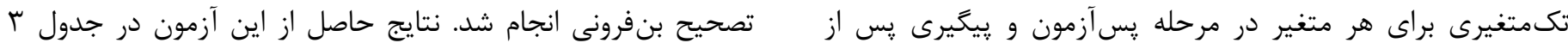

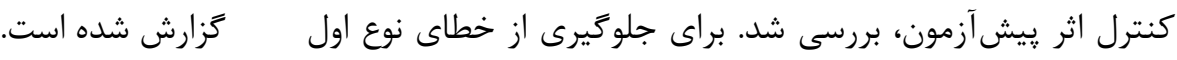

جدول ז. نتايج آزمون هاى جهار كانه تحليل كوواريانس براى متغيرهاى ثُوهش در مرحله بِ آزمون و بِيكيرى

\begin{tabular}{|c|c|c|c|c|c|}
\hline مجذورات & مقدار احتمال & $\mathbf{F}$ & مقدار & آزمون ها & منابع تغييرات \\
\hline.$|4| \Lambda$ &...$r$ & VIAFE &.$/ D F S$ & لامبداى ويلكز & \multirow{2}{*}{ مرحله يس آزمون } \\
\hline$\cdot|4| 1$ & 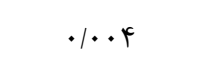 & V/AFS & $\cdot|V F|$ & بزرَتر ين ريشهروى & \\
\hline$\cdot / r V F$ & $\cdot \mu q$ & V/TIV & . IDHT & لامبداى ويلكز & \multirow{2}{*}{ مرحله ييكيرى } \\
\hline$\cdot \pi r y$ & 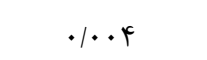 & V/TIV & . & بزركترين ريشهروى & \\
\hline
\end{tabular}

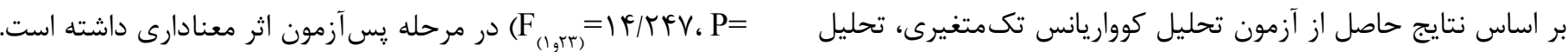
در نتيجه فرض صفر در سطح معنادارى ه•|• رد مىشود؛ به عبارت متغيرهاى استرس و اضطراب به تنهايى با استفاده از آلفاى ميزان شده ديكر با هو درصد اطمينان، درمان توانبخشى شناختى باعث كاهش

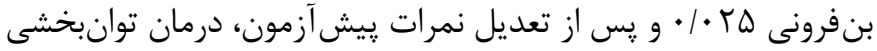
استرس و اضطراب نمونه مورد مطالعه يزوهش شده است (جدول بَ).

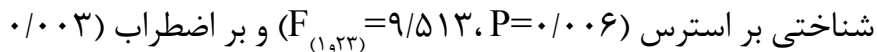
جدول r. نتايج تحليل كوواريانس تكمتغيرى براى استرس و اضطراب در مرحله يس آزمون با گواه پِيش آزمون

\begin{tabular}{|c|c|c|c|c|c|}
\hline مجذورات & مقدار احتمال & $\mathbf{F}$ & درجه آزادى خطا & df & متغير هاى وابسته \\
\hline . ITEF & $.1 \cdot .9$ & $9 / \Delta / r$ & r & 1 & استرس \\
\hline •/rVD & . & $\mid F / F F V$ & r & 1 & اضطراب \\
\hline
\end{tabular}

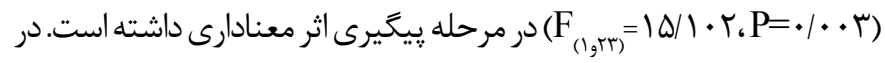
نتيجه مى توان عنوان نمود كه در مرحله ي پيخيرى، درمان توانبخشى شناختى اثر ماندَارى بر استرس و اضطراب نمونه مورد يزروهش داشته و بعد از حذشت

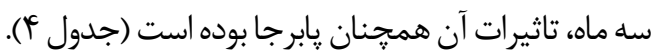

براساسنتايجحاصلازآزمون تحليل كوواريانس تكمتغيرى،تحليل متغيرهاى استرس و اضطراب به تنهايى با استفاده از آلفاى ميزان شده بنفرونى ه广 • /. و يس از تعديل نمرات پيش آزمون، درمان توانبخشى شناختى بر استرس (F) معنادارى داشته است، همجنين بر اضطراب (F,

جدول أ. نتايج تحليل كوواريانس تكمتغيرى براى استرس و اضطراب در مرحله يِخيرى با كنترل پِيشآزمون

\begin{tabular}{|c|c|c|c|c|c|}
\hline مجذورات & مقدار احتمال & $\mathbf{F}$ & درجه آزادى خطا & df & متغير هاى وابسته \\
\hline ./rq & $\cdot / \cdot \Delta$ & Q/ETI & זr & 1 & استرس \\
\hline$\cdot / r \wedge \mid$ & . & $10 / 1 \cdot r$ & r & 1 & اضطراب \\
\hline
\end{tabular}

ييش آزمون معنادار بود و در نهايت با توجه به اين كه سانوبت اندازهخيرى بيشتر وجود نداشت از انجام آزمون اندازهخيرى هاى مكرر صرف نظر گرديد.
از آنجايى كه تفاوت معنادارى بين دو مرحله يسآزمون و پييگيرى وجود

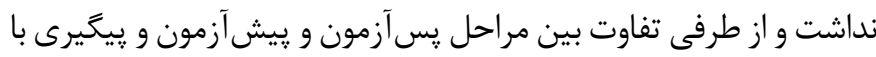


خود مى كند و در صورت درست انجام دادن بازى با دادن زتون و نشان دادن جهرههاى خندان آزمودنى را تشويق مى كند. نتايج يزوهش

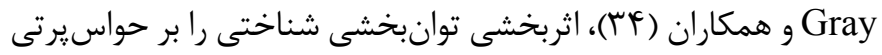

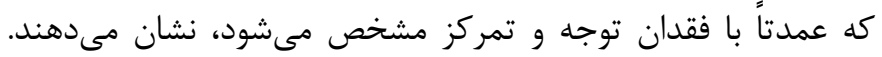

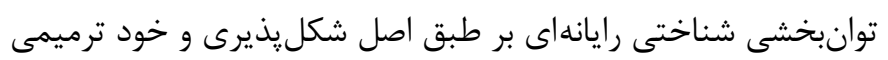

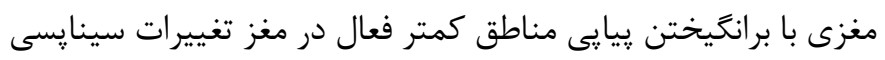

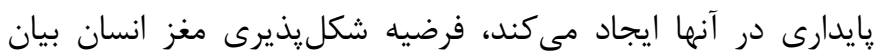
مى كند آر مناطق كمتر فعال درگير، به طور مناسب و مكرر تحريك إنى شوند اين تغييرات نمىتوانند موقتى باشند بلكه به دليل تغييراتى كه فرض مىشود در ساختار نورونها ايجاد كردهاند پايدار خواهند ماند. بنابراين با توجه به اين ارتباط تنكاتنگ، اثربخشى توانبخشى شناختى حافظه فعال كه كنشهاى اجرايى را مورد هدف قرار مى دهد بر بهبود نشانهاى اضطراب قابل تبيين است (ها؟).

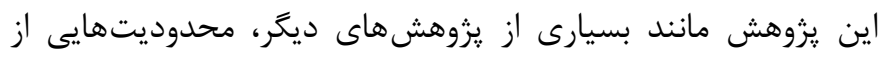
جمله محدوديت در روايى بيرونى داشت؛ نمونه يزوهش حاضر تنها

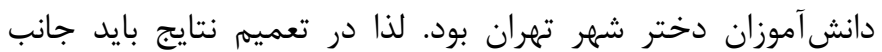

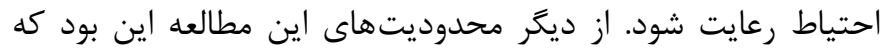
امكان ارائه مداخله براى گروه كنترل وجود نداشت.

\section{نتيجه كَيرى}

به طور كلى مىتوان نتيجه گرفت كه درمان توانبخشى شناختى

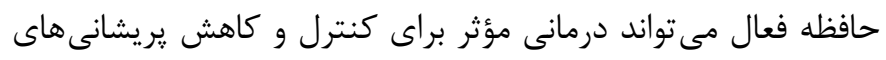

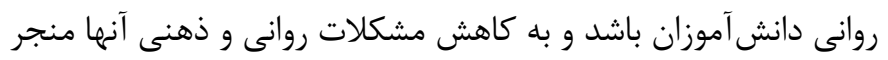

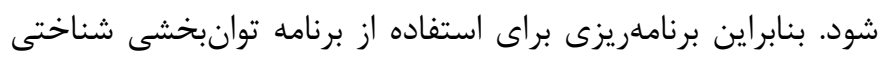

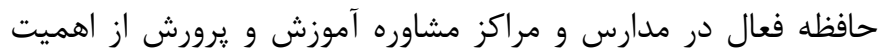

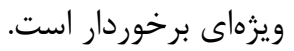

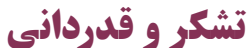

يزوهش حاضر بركرفته از يايان نامه بوده است. از تمامى شركت كنندكان و تمامى كسانى كه در اجر ایى يزوهش يارى كردند تشكر و قدردانى مى شود.
هدف يزوهش حاضر بررسى اثربخشى رواندرمانى توانبخشى شناختى

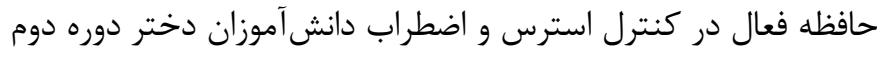
دبيرستان بود. نتايج نشان داد كه در مرحله يس آزمون و پِيگيرى، متغير

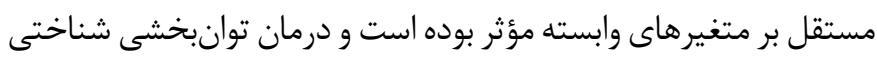

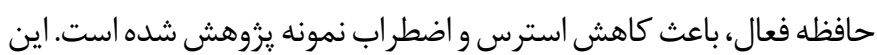
نتايج با يزوهش هاى قمرى كيوى و همكاران (YY)؛ رحمانيان و همكاران

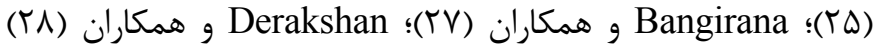
همسو است. درمان توانبخشى شناختى بر اصولى از شكليذيرى عصبى مغز مبتنى است كه شامل تمرينهاى هدفمند براى بهبود حوزههاى كوناكونِ شناخت مانند توجه، حافظه، زبان و كاركردهاى اجر ايى مى باشد (••"). برنامه توانبخشى شناختى رايانهاى به طور قابلتوجهى سرعت

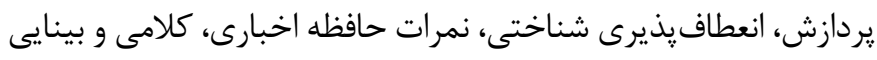

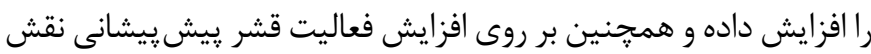

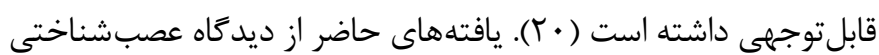
اين گونه قابل تبيين است كه كنشهاى اجرايى و بروز نشانهاى اضطرابى مناطق مشتركى را در مغز دركير مىسازند ( (آ). نتايج يزوهش ها همجنين نشان مى دهد توانبخشى شناختى حافظه فعال موجب كاهش اشتباهات سهوى و حواسيرتى شده است. حواسيرتى، يك يديده روانى است عوارض متعددى به دنبال دارد كه شامل افت در عملكردهاى حرفهاى و تحصيلى افزايش احتمال بروز

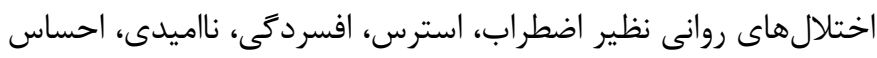

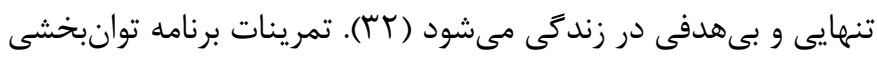

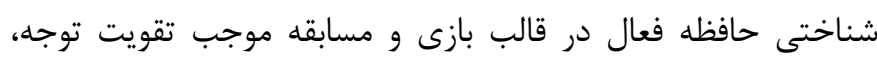
Captain's Log حافظه و حل مسئله مىشوند (بr). در نرمافزار برنامههاى يادآورى معكوس، تبعيض مفهومى و تركيب عددى نيازمند توجه و تمركز هستند در غير اين صورت آزمودنى قادر به انجام برنامه نخواهد بود. از اين رو اجراى اين برنامه موجب كاهش حواسيرتى آزمودنى مى شود. در تمام مراحل اين برنامه در صورت اشتباه آزمودنى آنى با نشان دادن علايم و جهرههاى عصبانى آزمودنى را متوجه اشتباه

\section{References}

1. Balderston NL, Quispe Escudero D, Hale E, Davis A, O’Connell K, Ernst M, et al. Working memory maintenance is sufficient to reduce state anxiety. Psychophysiology. 2016;53(11):1660-1668.

2. Robinson OJ, Vytal KE, Cornwell BR, Grillon C. The impact of anxiety upon cognition: Perspectives from human threat of shock studies. Frontiers in Human Neuroscience. 2013;7:203. 3. Clark DA, Beck AT. Cognitive theory and therapy of anxiety 
and depression: Convergence with neurobiological findings. Trends in Cognitive Sciences. 2010;14(9):418-424.

4. Eysenck MW, Derakshan N, Santos R, Calvo MG. Anxiety and cognitive performance: Attentional control theory. Emotion. 2007;7(2):336-353.

5. Luo X, Zhang L, Wang J. The benefits of working memory capacity on attentional control under pressure. Frontiers in Psychology. 2017;8:1105.

6. Wilson MR, Vine SJ, Wood G. The influence of anxiety on visual attentional control in basketball free throw shooting. Journal of Sport and Exercise Psychology. 2009;31(2):152168.

7. Edwards MS, Moore P, Champion JC, Edwards EJ. Effects of trait anxiety and situational stress on attentional shifting are buffered by working memory capacity. Anxiety, Stress, \& Coping. 2015;28(1):1-6.

8. Wood G, Wilson MR. A moving goalkeeper distracts penalty takers and impairs shooting accuracy. Journal of Sports Sciences. 2010;28(9):937-946.

9. Nieuwenhuys A, Oudejans RR. Effects of anxiety on handgun shooting behavior of police officers: A pilot study. Anxiety, Stress, \& Coping. 2010;23(2):225-233.

10. Causer J, Holmes PS, Smith NC, Williams AM. Anxiety, movement kinematics, and visual attention in elite-level performers. Emotion. 2011;11(3):595-602.

11. Navarro M, Miyamoto N, Van Der Kamp J, Morya E, Savelsbergh GJ, Ranvaud R. Differential effects of task-specific practice on performance in a simulated penalty kick under high-pressure. Psychology of Sport and Exercise. 2013;14(5):612-621.

12. Kaneda M, Osaka N. Role of anterior cingulate cortex during semantic coding in verbal working memory. Neuroscience Letters. 2008;436(1):57-61.

13. Hoffman R, Al'Absi M. The effect of acute stress on subsequent neuropsychological test performance (2003). Archives of Clinical Neuropsychology. 2004;19(4):497-506.

14. Akirav I, Kozenicky M, Tal D, Sandi C, Venero C, Rich-
ter-Levin G. A facilitative role for corticosterone in the acquisition of a spatial task under moderate stress. Learning \& Memory. 2004;11(2):188-195.

15. Tuholski SW, Engle RW, Baylis GC. Individual differences in working memory capacity and enumeration. Memory \& Cognition. 2001;29(3):484-492.

16. Repovs G, Baddeley A. The multi-component model of working memory: Explorations in experimental cognitive psychology. Neuroscience. 2006;139(1):5-21.

17. Wolf OT. Stress and memory in humans: Twelve years of progress?. Brain Research. 2009;1293:142-154.

18. Schwabe L, Wolf OT, Oitzl MS. Memory formation under stress: Quantity and quality. Neuroscience \& Biobehavioral Reviews. 2010;34(4):584-591.

19. Hornung C, Brunner M, Reuter RA, Martin R. Children's working memory: Its structure and relationship to fluid intelligence. Intelligence. 2011;39(4):210-221.

20. Han G, Helm J, Iucha C, Zahn-Waxler C, Hastings PD, Klimes-Dougan B. Are executive functioning deficits concurrently and predictively associated with depressive and anxiety symptoms in adolescents?. Journal of Clinical Child \& Adolescent Psychology. 2016;45(1):44-58.

21. Susman EJ, Dorn LD. Puberty: Its role in development. In Lerner RM, Steinberg L, editors. Handbook of adolescent psychology. 3rd ed. New Jersey:John Wiley \& Sons, Inc;2009. pp. 116-151.

22. Romeo RD. Adolescence: A central event in shaping stress reactivity. Developmental Psychobiology. 2010;52(3):244-253. 23. Rudolph KD. Gender differences in emotional responses to interpersonal stress during adolescence. Journal of Adolescent Health. 2002;30(Suppl 4):3-13.

24. Qamari Givi H, Nader M, Dehqani F. The effect of cognitive rehabilitation on the reconstruction of executive functions of OCD patients. Clinical Psychology Studies. 2014;4(16):101128. (Persian)

25. Rahmanian M, Mohtarami S, Dehestani M. The effect of cognitive rehabilitation training on improving anxiety symp- 
toms in children. Quarterly Journal of Child Mental Health. 2018;5(1):48-58. (Persian)

26. Cheng C, Liu X, Fan W, Bai X, Liu Z. Comprehensive rehabilitation training decreases cognitive impairment, anxiety, and depression in Poststroke patients: A randomized, controlled study. Journal of Stroke and Cerebrovascular Diseases. 2018;27(10):2613-2622.

27. Bangirana P, Giordani B, John CC, Page C, Opoka RO, Boivin MJ. Immediate neuropsychological and behavioral benefits of computerized cognitive rehabilitation in Ugandan pediatric cerebral malaria survivors. Journal of Developmental and Behavioral Pediatrics. 2009;30(4):310-318.

28. Derakshan N, Eysenck MW. Anxiety, processing efficiency, and cognitive performance: New developments from attentional control theory. European Psychologist. 2009;14(2):168-176.

29. Sahebi A, Asghari MJ, Salary RS. Validation of depression anxiety and stress scale (DASS-21) for an Iranian Population. Journal of Developmental Psychololy. 2005;1(4):36-54. (Persian)

30. Maggio MG, De Luca R, Molonia F, Porcari B, Destro M, Casella $\mathrm{C}$, et al. Cognitive rehabilitation in patients with traumatic brain injury: A narrative review on the emerging use of virtual reality. Journal of Clinical Neuroscience. 2019;61:1-4.
31. Wehry AM, Beesdo-Baum K, Hennelly MM, Connolly SD, Strawn JR. Assessment and treatment of anxiety among children and adolescents. Current Psychiatry Reports. 2015;17(7):591. 32. Bergo E, Lombardi G, Pambuku A, Della Puppa A, Bellu L, D'Avella D, et al. Cognitive rehabilitation in patients with gliomas and other brain tumors: State of the art. BioMed Research International. 2016;2016;3041824.

33. Gaitan A, Garolera M, Cerulla N, Chico G, Rodriguez Querol M, Canela Soler J. Efficacy of an adjunctive computer based cognitive training program in amnestic mild cognitive impairment and Alzheimer's disease: A single blind, randomized clinical trial. International Journal of Geriatric Psychiatry. 2013;28(1):91-99.

34. Gray SA, Chaban P, Martinussen R, Goldberg R, Gotlieb H, Kronitz R, et al. Effects of a computerized working memory training program on working memory, attention, and academics in adolescents with severe LD and comorbid ADHD: A randomized controlled trial. Journal of Child Psychology and Psychiatry. 2012;53(12):1277-1284.

35. Abbariki A, Yazdanbakhsh K, momeni Kh. The effectiveness of computer-based cognitive rehabilitation on reducing cognitive failure in students with learning disability. Quarterly of Psychology of Exceptional Individuals. 2017;7(26):127-157. (Persian) 